\title{
THE SURGICAL MANAGEMENT OF PERIPHERAL VASCULAR DISORDERS-I
}

\author{
By Sol. M. Cohen, M.A., Cape Town, F.R.C.S. \\ (Surgeon in Charge of a Surgical Division at an E.M.S. Hospital)
}

THE YEARS BETWEEN the wars were fruitful ones for vascular surgery. The assiduous and painstaking work of Lewis and his co-workers, brought us a better understanding of the normal and abnormal behaviour of vessels. Skin and muscle circulations were studied, and much was learnt concerning the management of the limb in the ischaemic state. Their work will for all time be a living stimulus and an example to others. Late in the twenties came the surgery of the sympathetic system; its scope and possibilities seemed tremendous. Even Lord Moynihan-at an age when man is mellow, and when what is new is not regarded as necessarily true-joined in the singing of the words of an unknown Irish poet "each age is a dream that is dying, or one that is coming to birth." This was the physiological era of surgery come to birth. The dreams of sympathetic surgery have not been fully realised; but no matter, it has given us a fuller appraisal of the indications, and above all the limitations, of its surgery. As the prospect of another war of freedom loomed before us, men's minds turned again to a study of shock-shadow of death itself. It would be surgical pomp to say that we understand shock, but it is fair justice to many of the workers, especially in this war, to say that our eyes do see somewhat more clearly into that darkness. We do know that the general condition, by rationing the limb blood supply, oft is the determining factor as to whether death of the limb supervenes; absorption from the dying avascular muscle mass may profoundly influence the general condition and the renal state of the patient. Just before this war heparin was introduced into clinical therapeutics, and a vast new field thereby opened. Its possibilities have only been lightly touched; the wounds of war are so often multiple and conditions of surgery urgent, that it is not often that favourable opportunities present themselves for its use. In the years between, Garrod was a prophet predicting that chemotherapeutic agents would be found to destroy organisms and not life. "The greatest antiseptic of all is living tissue," wrote the discoverer of penicillin. Ischaemic tissues are easy prey for infection, and sepsis haunted the vascular surgeon's strides. Sulphonamides and particularly penicillin came as a great addition tò the surgeon's armamentarium. But progress is not always marked by a straight line. There are side channels which divert, lure, and draw even the best of surgical captains. Between the wars it became rather popular to invoke a number of vascular reflexes as responsible for limb deaths $\overrightarrow{\overrightarrow{\vec{A}}}$ pathological collateral vessel spasm, reflex spasi from the arterial bruise, and other reflexes fron venous channels are still being argued abouts. But such speculations are of some purpose; fom they teach us to think and argue. Ever to main ${ }_{\bar{\tau}}$ tain an "active doubt," and above all, teach ouf tongues to say "I don't know." The test o $\vec{\Phi}$ greatness, and it is a hard lesson, is to be able to say as John Hunter did, "very likely I did say sक्छ a year ago, but I think differently now."

Before surveying in detail some of the arteriat lesions it is profitable to peep at some of the trends. in vascular surgery and see what the future has in store for us. Very recently, following the physicochemical researches of Professor Cohn ${ }^{1}$ at Harvard, the haemostatic fraction of blood has been isolated. Known as "fibrin foam" it has found a place already for the bleeding vessel in surgery of the liver and of the brain. Its use in limb surgery, especially for glueing sutured vessed lines, seems certain. Particularly pleasing are the reports that experimentally it causes no logado inflammatory tissue reaction. Heparin has 通产 but small clinical trial. The intravenous methodsis cumbersome; patients vary in their responses and repeated clotting time estimations are essential? A method of subcutaneous administration has novw been introduced and is on clinical trial. Loew and his associates ${ }^{2}$ have shown that in Pitkin's. menstruum, heparin may be deposited subo cutaneously once in 48 hours, and a steady uni form release of heparin obtained without need fog regular clotting time estimations. At last, too we appear to have a safe non-irritating contras? medium for limb arteriography, an organic iodine compound-diodone (Perabrodil, Pyelosil)-and it is certain we shall learn much from this method. To build new arteries from old veins is a stimus lating thought in itself; and the recent work of Blakemore and Lord, ${ }^{3}$ using vitallium cannulae through which are threaded vein segments, has now given us a safe practical technique. Nature. makes that vein into an artery.

Peripheral vascular lesions may be "pigeon holed" into three main groups. The commone尺 disorders only will be considered:-

Traumatic

Division; contusion; occlusion-by locał pressure or spasm. Arterial and arterio venous aneurysm.

Organic

(a) Degenerative:Arteriosclerosis-hypertensive, senil diabetic; Mönckeberg's sclerosis. 
(b) Inflammatory:-

Thromboangiitis obliterans (Buerger's disease); localised arteritis; syphilitic endarteritis; periarteritis nodosa.

(c) Vascular accidents: embolism; thrombosis - costoclavicular compression ("Cervical rib vascular complications").

Functional (a) Vasoconstrictor:-

"Raynaud's phenomenon"; sclerodactyly; acrocyanosis; erythrocyanosis frigida; perniosis (chilblains) "Pneumatic hammer" disease; minor causalgia.

(b) Vasodilator:-

Erythralgia; post-traumatic painful syndromes; immersion foot (hyperaemic stage).

\section{Clinical Considerations.}

To Lewis and his co-workers we are indebted for a number of fundamental facts about the ischaemic limb. They showed that on occlusion of the main blood supply the skin temperature of the limb gradually falls, and finally, owing to evaporation, will be slightly below room temperature. There is no sudden cooling and in a warm bed it takes many hours for that limb to cool down -even up to 20 hours. With the ischaemia, metabolites in the skin call forth the dilatation of all the available fine superficial vessels. These part with their oxygen, and the warmer the limb the more readily does the oxyhaemoglobin dissociate. Within a few minutes such an arterial obstructed limb may be deeply cyanosed. The tyro oft misinterprets this cyanosis as due to venous obstruction only. Heat, we also know, steps up the metabolism of the struggling cell and increases its oxygen needs; and these cannot be met. In recent years the danger of heating such anoxic tissues, has become appreciated generally. Unfortunately, however, from excess heating there has been a rebound to excess cooling, and ischaemic limbs are being oft encased in ice or severely cooled. Such icing is dangerous, for it must not be forgotten that below $60^{\circ} \mathrm{F}$. (10 ${ }^{\circ} \mathrm{C}$.) oxyhaemoglobin will not dissociate and part with its oxygen. Treatment within physiological temperatures must always be the guiding rule.

Tissues with specialised function cannot withstand for long the loss of blood supply. Muscle, we believe, dies within 6 hours; if kept cool it may survive possibly Io hours. Nerve will withstand I2 to 20 hours vascular arrest and still recover. Skin is even more resistant, and 24 , even 48 hours loss of blood supply may not affect it. The first sign of skin damage shows itself by whealing or blistering, and later the development of dark patches beneath the blister sites. The nutritional demands of skin are small; its multitude of fine interlacing vessels serve to a great extent as a radiator surface for the regulation and maintenance of a constant body temperature. The range of blood flow in the normal skin thus is considerable, and Goetz, ${ }^{4}$ using an optical plethysmograph, has shown that it may vary from 94 c.c. per minute per Ioo c.c. tissue with full dilatation to 3 c.c. with maximal vasoconstriction. The minimal metabolic need of skin has been estimated by Burton ${ }^{5}$ to be I c.c. per minute per Ioo c.c. tissue. Although muscle and nerve may be alive after many hours of vascular arrest, it is well to observe that after $I_{5}$ to 30 minutes complete ischaemia, nerve conduction ceases. Nerve conduction is an active metabolic process; there is utilisation of oxygen and production of heat; and as Bentley and Schlapp ${ }^{6}$ have recently shown experimentally, an active circulation is required to maintain normal nerve function. The peripheral muscles - of the hands and feet-fail first, and at the same time sensory loss develops. The latter is often overlooked; it follows no nerve distribution, and is usually stocking or slipper, or glove in distribution.

Lewis and his co-workers háve shown also that the components of a mixed nerve vary in their sensibility to anoxia; that fibres subserving slow conducted pain, and vaso-motor, sudo-motor, and pilo-motor fibres are more tolerant to ischaemia. This accounts for the unpleasant sensory effects, such as the slow prolonged pain response on pressure in the recovery stage of the ischaemic limb.

The pain of the ischaemic limb has been investigated, and two types of pain may be distinguished, (I) exercise pain, (2) rest pain. Lewis and his co-workers have shown that the pain on exercising the ischaemic limb-intermittent claudicationis not due to vessel cramp (these vessels are in fact dilated); nor is it due to oxygen lack-but is consequent on the muscle contraction and is due to the accumulation of a chemical agent "factor P" in the tissue spaces, which stimulates the sensory nerve endings. A quantitative level of factor $\mathbf{P}$ appears to be necessary for such pain to appear. With the return of the circulation, or cessation of the exercise, the level of factor $P$ rapidly falls, or it is transformed so that it is no longer pain producing. When the limb has been exercised prior to complete vascular arrest, exquisite agonal pain may thus continue to be the lot of the patient. On the other hand, with the limb at rest at the time of vessel occlusion, numbness, coldness, or a dead feeling alone will be complained of.

- The "rest" pain of the ischaemic limb is as a rule associated with cyanosis of part of the foot or toe or hand, and gangrene seems imminent. These patients sit up in bed rubbing and hugging the affected extremity and are in agony. At night the pain is oft worse and the patient will walk the 


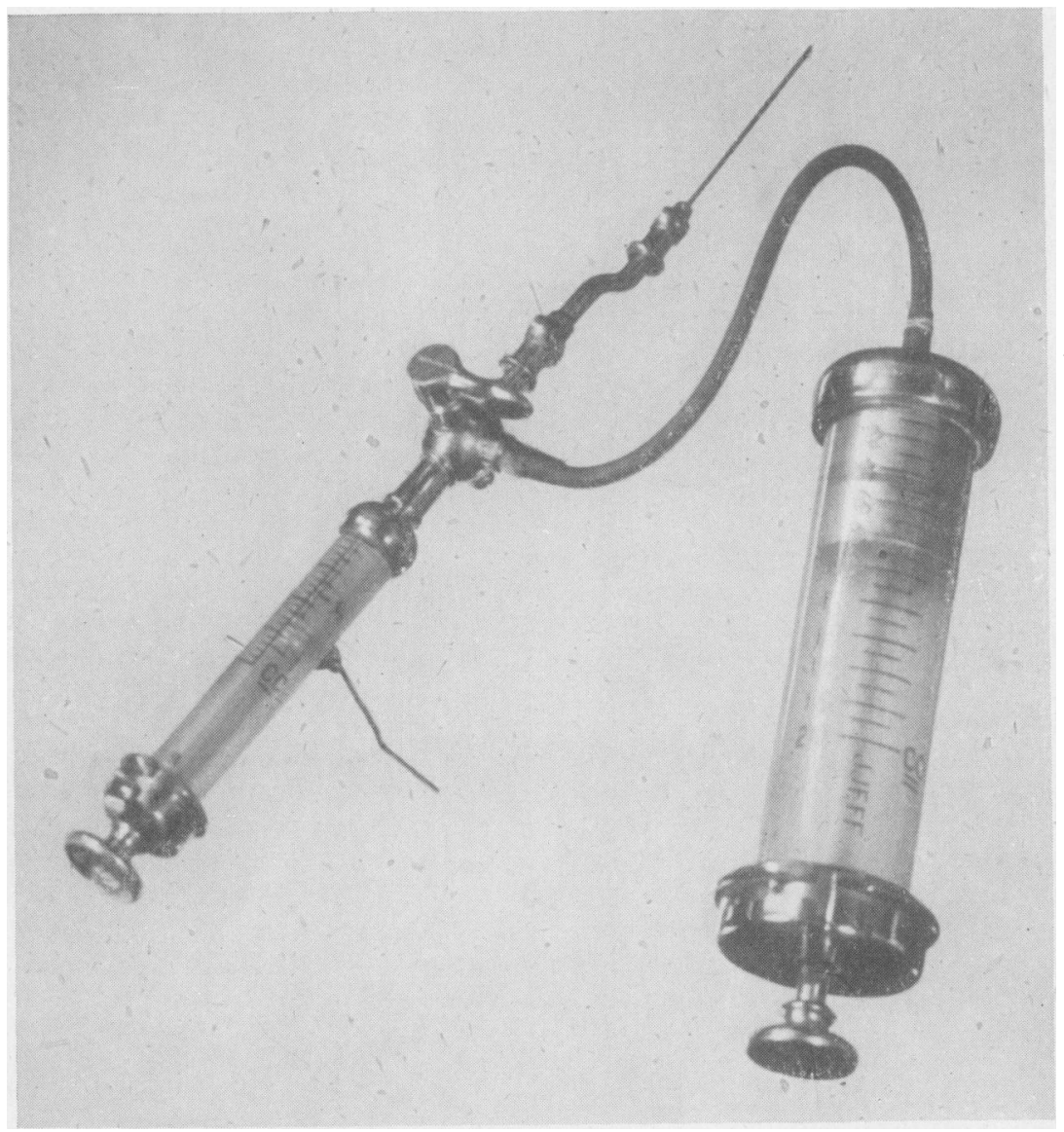

ARTERIOGRAPHY "SET-UP." - The two-way tap enables the operator to aspirate and steady the needle; the tap is turned, and the assistant rapidly injects the contrast medium. The surgeon, with one hand free, can compress the artery or vein proximal to the injection point. 

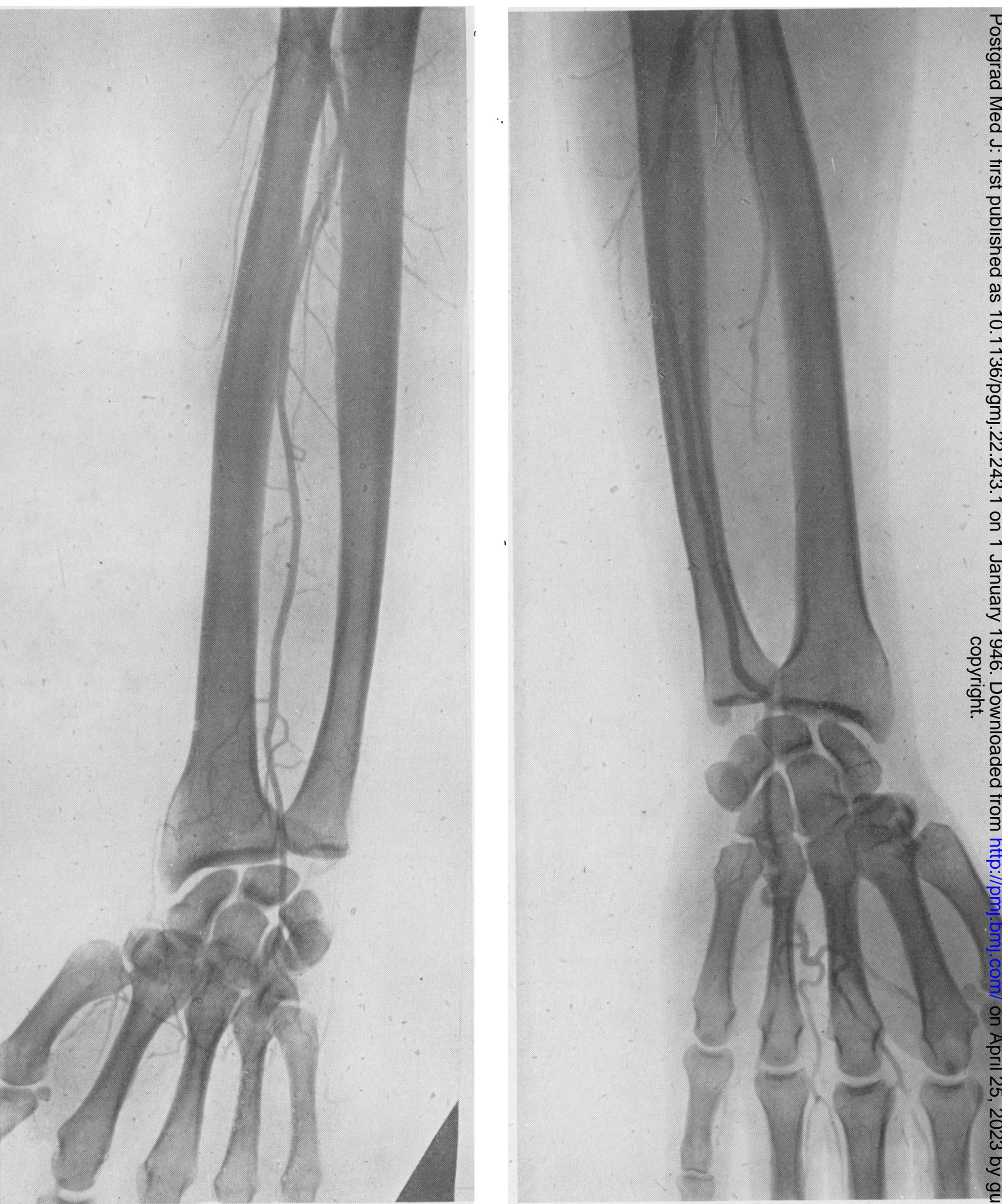

Right arm.

ARTERIOGRAM-Thromboangiitis Obliterans.

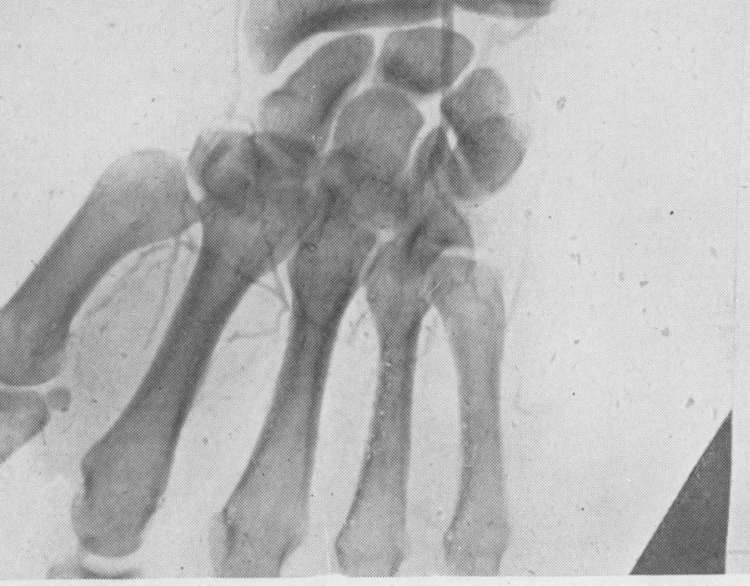

I. (Right arm.)-Circulation of hand"being maintained by dorsal interosseous artery. Radial artery seen as thin streak $\frac{D^{\circ}}{\square}$ Ulnar artery present in "the proximal third only. Has "intermittent claudication" of forearm.

2. (Left arm.) -Ulnar artery sole supply to the hand. Radial artery completely absent, and dorsal interosseous fade out. Note "drum stick" ends on some of the collaterals. 
room all night to try to obtain relief. The cause of the pain is obscure, but the explanation recently indicated to account for the causalgic lesion (Doupe, Cullen and Chance) ${ }^{7}$ may well fit here. That the sympathetic and sensory fibres run close together in their final distribution is well known-they suggest, therefore, that the defective terminal circulation interferes with the "insulation" of the fibres and cross stimulation can occur. The efferent sympathetic impulses then continue to stimulate the sensory fibres. The feasibility of this explanation is in accord with the remarkable immediate relief oft obtained in such cases by sympathectomy.

Telford, ${ }^{8}$ too, has been impressed by the dramatic and most satisfactory results of sympathectomy for this type of pain. He regards it as a "starvation pain due to increasing digital thrombosis," and points out that only when thrombosis is not too advanced and some vasodilatation is yet possible is the greatest relief obtained. The relief of pain he attributes to the improved local circulation. Such rest pain thus requires early sympathectomy. To be distinguished from such "rest" pain are the local painful effects of ischaemic ulceration and gangrene. Oft overlooked as a cause of this local pain are the effects of sepsis such as a spreading tendon sheath infection.

Just as the pains of muscle and skin ischaemia are provoked in different manner, so, it is being increasingly recognised, are the skin and muscle circulations controlled by different mechanisms. Thus measures which increase the skin circulation, such as paravertebral block, spinal anaesthesia, or opposite limb heating, will not affect the muscle circulation. The cold skin may have beneath it an active muscle circulation; or the warm limb have dead muscles. The muscles of the calf may be ill-supplied-intermittent claudication-and yet the skin circulation of the foot be fully adequate. The most powerful stimulus for muscle vessel dilatation is exercise. For skin, body warming produces the maximum vasodilation; the blood flow to the fingers may be increased roo times by such warming, and the increased blood flow produced by this means is greater than by local heating (Wilkins, Doupe, and Newman). ${ }^{9}$ Skin and muscle circulations, as Silbert ${ }^{10}$ has shown, also respond differently to various drugs. Adrenalin will cause marked skin vasoconstriction and a decreased flow in the hand and fingers, and yet an increased flow in the muscles of the forearm. Smoking will decrease the flow in the fingers and hand-and yet the forearm flow be unaffected. Nature, too, is lavish in her blood supply to the limbs. Kunkel and Stead, ${ }^{11}$ and Abramson ${ }^{12}$ have shown by plethysmographic studies of blood flow in arteriosclerotic and thromboangiitis cases, that the maximal blood flow in a limb may be reduced
50 per cent without any symptoms or signs. $\frac{0}{0}$ With such a vascular reserve available-and in the skin as Goetz points out, it ranges from 3 c.c. $\frac{3}{\Phi}$ to 94 c.c. per Ioo c.c. tissue-there may still be $\varrho$

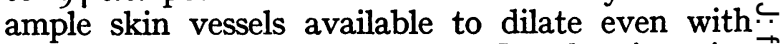
extensive deep disease. On reflex heating-i.e. $\overrightarrow{\bar{F}}$ opposite limbs-a satisfactory temperature rise thus may be demonstrated in the affected limb $\frac{\mathrm{C}}{0}$ and yet there be grave arterial disease within the $\frac{\overline{\bar{N}}}{\bar{B}}$ deeper vessels.

\section{Arterial Disorders and the Sympathetic ${ }_{-}^{\stackrel{D}{\infty}}$ Nervous System.}

A number of physiological facts about the sympathetic system have become clearer. The sympathetic supply to the limb is best viewed as an effector mechanism-one of a number-for controli of the circulation. No afferent fibres have been $N$ demonstrated, and the relief of pain after sympathectomy is believed to be due purely to its. local vascular effects rather than the section of anyo pain fibres. Distribution of sympathetic fibres is in the main to the skin blood vessels and sweatc glands, and in their final distribution these fibres follow closely the sensory branches. These facts suggest that the sympathetic supply is concerned mainly with the regulation of body temperature. $\overrightarrow{0}$ The fibres to the deeper vessels are relatively feuvos in number; and we know that such a vessel wall plexus receives its branches from the main somateo nerves, as the latter descend. These sympathetic fibres around the main vessel apparently rarely come into action except in states of emergency, $\frac{}{\mathbb{D}}$ such as shock or asphyxia. There has always been doubt as to the presence of vasodilator fibresô in the human, but recent opinion appears to show that they do exist. The immediate effect of sympathectomy in a suitable case is a dry warmed skinned limb; but it has become clearer, within흑 recent years, that the blood supply to the muscles-: is thereby but little improved. Friedlander and 3 . his associates ${ }^{13}$ have studied this by inserting. electrodes into muscles and noting the effects of $\frac{}{3}$ paravertebral sympathetic block. Grant and Pearson $^{14}$ have confirmed this by plethysmographic studies. Barcroft and his colleagues ${ }^{15}$ have demon- $\frac{D}{O}$ strated that with full sympathetic release the rise of $=$. blood flow in the muscles is only about I/I3th that N produced by the dilatory action of the muscle meta- $N$ bolites, as in exercise. The application of these $\mathrm{N}$ physiological findings is evident. Muscle circulation $\mathrm{\omega}$ insufficiencies - such as intermittent claudicationwill thus be but little improved by sympathectomy whereas skin nutritional disturbances, rest pain, threatened gangrene or ulceration, will reap the ${ }^{+}$ greatest benefit. As the digits have no muscles, the $\frac{0}{0}$ blood flow in the fingers or toes-and to a slightly 
lesser extent the hand and foot-is regarded as skin circulation. Professor Telford ${ }^{\mathbf{8}}$ has recently analysed his sympathectomy results in a large series of cases, and we shall be discussing some of his findings when we come to the various clinical diseases.

Two further facts of great surgical importance have emerged within recent years from the study of such clinical cases. Firstly, most surgeons now do "preganglionic" sympathectomies. It is of interest as to how this came about. Shortly before this war all vascular workers began to realise that a large number of sympathectomy results-mostly upper limb-although at first apparently very satisfactory, later were disappointing and back at their pre-operation state. All these cases had extensive removal of the ganglia. The day after operation the limb felt warm, but towards the end of a week the limb temperature began to drop and some three weeks after operation the limb felt cooler than normal, and cold or emotional stress brought on a state of vasospasm. White, Grant, Freeman, Smithwick, and others, took up the subject, and it soon became clear that in line with the behaviour of unstriated muscle in general, the denervated arterial wall had become abnormally sensitive to circulating adrenaline-like substances circulating in the blood, generally referred to as sympatheticomimetic hormones. Soon it was shown that if the ganglia were left intact much of this abnormal sensitivity could be avoided, and carefully planned pre-ganglionic section operations came to be introduced. Secondly, the great variations in the anatomy of the sympathetic tree came to be appreciated; the pattern of the ganglia varied, and there was an inconstant arrangement of the rami communicantes. Telford has recently therefore advocated that the extent of the sympathectomy operation be defined in terms of vertebral level section, rather than numbered ganglia. Thus he advises "for the upper limb a section of the thoracic chain at or just below the neck of the third rib with dislocation of the cut ends to prevent union. For the lower limb an excision of the lumbar chain for a length of one and a half to two inches centred opposite the body of the 3rd lumbar vertebra." It is known that the sympathetic supply to the upper extremity passes out by way of the anterior nerve roots and white rami, into the 3 rd to the Ioth thoracic sympathetic ganglia-thence they stream upwards to be relayed in the upper 3 ganglia and hence to the limb. Section caudal to the 3 rd ganglion and division of its white ramus is thus adequate. The operation is best carried out via the anterior approach as first described by Gask and Ross. ${ }^{16}$ In America a rather more extensive operation is practised-as advocated by Smithwick;17 besides dividing the sympathetic chain as above, the posterior parts of the second and third intercostal nerves are resected to ensurê⿳亠丷厂犬 the removal of any pre-ganglionic fibres emerging in these nerve roots. A posterior approach is utilised, and the posterior part of the 3 rd rib and transverse process excised. Recent opinion, how ever, questions the need for this more extensive procedure. It is well to note that the modere operation leaves the stellate ganglion intact and thus avoids the Horner's syndrome with its rathe ugly, unpleasant effects.

Sympathectomy for the lower limb lesion has్ not presented any hypersensitivity problems for by accident, rather than design, the operation $\vec{b}$ has always been pre-ganglionic in type. The mair somatic nerve of supply below the knee is the sciatic, and its accompanying vasoconstricto fibres have their cell stations in the 4th lumbat ganglion and the three sacral ganglia. To excise the lumbar chain in the region of the 3 rd vertebra (as Telford advocates) is thus to do a pre-ganglionic section. Admittedly, with this excision, which embraces the 2nd and 3 rd lumbar ganglia, some of the post-ganglionic fibres to the femoral and obturator nerves are severed, but their above knee supply effect is minor. It is now well recognised? too; that the first lumbar ganglion must not be removed, for that may lead to sterility-not impotence-as it interferes with the mechanismoto ejaculation. Lake ${ }^{18}$ recently has been able प्रेक show that the usual sympathectomy operation does not affect the semen count; a fact of $1 \mathrm{mp}$ portance for a plea of sterility as consequent on such an operation has been legally tendered. The्e extra-peritoneal approach is undoubtedly the mor satisfactory and is becoming increasingly popular It requires no packing of bowel, and patients have an easy convalescence. The only disadvantage is that if a bilateral operation is necessary it has tof be done in two stages-at three weekly intervals:But the patients rarely raise objections. The incision, most useful, is a slight modification of that recommended by Gask and Ross. ${ }^{16}$ The incision runs in line from the tip of the twelfthr. rib to a point one inch below the umbilicus. Aftes dividing the skin, a muscle splitting incision opening into the rectus sheath is all that is needed. A? spinal anaesthetic (heavy Nupercaine $I \cdot 8$ c.c. $\frac{D}{0}$ and the patient asleep) is advisable. Lastly, the risk of "regeneration" after operation has been strongly stressed, and great pains have been taken to swing and bury or even seal the cut sympathetic chain ends. It is well to note, therefore, that Telford, in $w$ the wisdom of his extensive experience, is doubtfure as to the possibility of any such regeneration.

\section{Clinical Investigations.}

The decision for surgery will depend on carefulf clinical investigations, and the surgeon must定 
primarily be a physician. The limb should be examined elevated, horizontal, dependent. The limb that whitens excessively on elevation or exercise has an inadequate circulation, for it shows that the superficial veins carry atway blood more quickly than it can be replaced. Samuels, ${ }^{19}$ who has had extensive experience of organic vascular disease, finds such observations the most valuable of all clinical signs, and uses it as a test of circulatory efficiency in the lower limb. With the patient lying down and the limb arranged at an angle of $45^{\circ}$, he is asked to extend and flex vigorously both feet at the ankle joints. The soles of feet are closely observed. "In the presence of arterial occlusion, even of minimal degree, a decided pallor soon develops" (Samuels). This plantar ischaemia -oft referred to as Goldflamm's sign (for he described it with the limb in horizontal position) may be so marked in the advanced cases that the foot has a cadaveric appearance. On dependency, the deficient circulatory limb takes on a dusky red appearance, this being due to lack of tone in the capillaries. Marked "rubor"--as it is knownusually indicates arterial disease of advanced degree. Examination of the pulses gives valuable information -it is to be noted that the blood pressure in the leg is always higher than in the upper limb. The dorsalis pedis is absent in 14 per cent of normals, frequently it is found displaced; the peroneal artery replaces the posterior tibial in 5 per cent of normals. (Kramer). ${ }^{20}$ The popliteal vessels should always be palpated, and this is easily done if the knee be flexed and the foot allowed to rest on the bed. In thromboangiitis obliterans, as Telford has pointed out, the associated periarteritis may cause a firm fibrous mass to be felt in the popliteal fossa. It is also now more generally recognised that the blanching response, on local capillary circulation pressure, is not an efficient guide, since a poor response may be obtained with an adequate circulation. Watching the filling of the veins is, however, of value. The limb is elevated, then allowed to hang down and the filling of a selected vein timed. The normal filling time is $5-7$ seconds; with organic disease it may take many minutes (Collens and Wilensky).21 Lastly, Lewis, in his wisdom, has stressed the general principle that a symptom under investigation should, if possible, be provoked in the presence of the investigator.

Three other tests of limb circulation may be easily performed:-

(I) Lewis's ${ }^{286}$ reactive hyperaemia test (tourniquet test). Here the limb, warmed in hot water $\left(95^{\circ} \mathrm{F}\right.$.) for Io minutes, is elevated, and lightly stroked until the skin is pale. A blood pressure cuff is applied and inflated. The exsanguination is maintained for 5-1o minutes with the limb in water.

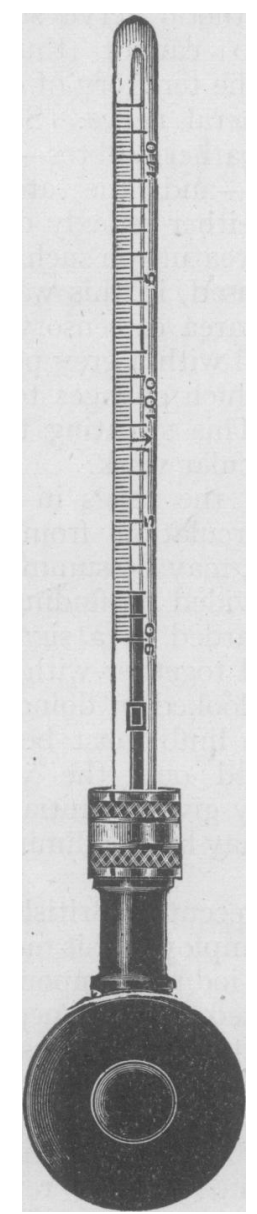

SkIN THERMOMETER as used in testing rise in skin temperature $\vec{\omega}$ following reflex heating. This thermometer is lightly strapped to the foot.

On releasing the tourniquet the circulatory return may be closely observed. Blood pours into the dilated vessels (due to accumulated metabolites) and the area of arterial poverty fills slowly or poorly and is well mapped out. Normally the 3 . circulation will have returned fully within 3 to $5 \frac{9}{3}$ seconds, and the skin be evenly flushed.

(2) Skin temperature test. The method of 8 "reflex" heating is now commonly employed; spinal anaesthesia or typhoid vaccine injections 9 are no longer considered necessary. An arm or $>$ both feet are placed in warm water at $110^{\circ} \mathrm{F}$. and readings taken every 5 minutes. The im- N proved ring surface skin thermometer gives adequate clinical information, and is useful, $\widetilde{O}$ especially these days when thermocouples are $\underset{\omega}{\mathscr{W}}$ scarce.

The warmed blood from the limb proceeds toc the extremely sensitive heat regulating centres in $\bar{\Phi}$ the hypothalamus; these respond by inhibiting.? the normal central vasoconstrictor impulses to 7 the skin vessels. Such reflex dilation therefore 
depends on an intact sympathetic nerve supply. The sympathectomised limb cannot thus be reflexly vasodilated; nor can the territory of distribution of the divided peripheral nerve. Section of the latter divides the sympathetic fibres-vasoconstrictor and sudo-motor-and the area of cutanecus distribution thus neither reflexly dilates nor sweats. The absence of sweating on such reflex heating has been commonly used, in this war, for mapping out objectively the area of sensory loss. The area to be tested is dusted with a grey powder (Chinizarin dye-Guttman) which changes to redpurple with any moisture. This sweating test is a useful one in peripheral vascular work.

We have already discussed the snags in interpreting the state of the circulation from skin temperature observations. It may be summed up - the method is of value provided its findings are not overrated, and it be regarded as a sign that takes its place and is weighed together with other findings. A point often overlooked in doing such temperature tests is that the limb must be horizontal-as Goetz has pointed out, the venous congestion of dependency may give an initial false high reading in a limb which may have a diminished blood flow.

(3) Arteriography. Until recently British surgeons have only occasionally employed this method. The introduction of organic iodine compoundsas in pyelography-constituted an advance, but as some of these were irritating and used in hypertonic concentrations, serious sequelae at times followed such intra-arterial injection. Thorotrast came to be introduced; but it was shown that it was taken up by the reticuloendothelial system and held in the liver and spleen for many years. Besides it was radio-active-a picture of the spleen could be cast on a photographic plate-and there was thus a risk of malignant change. Recently, the newer organic iodine compound-diodone (Pyelosil, Perabrodil) has been used-it is non-irritating and may be injected subcutaneously and spilled in the tissues without necrotic effect. Learmonth ${ }^{22}$ has fully described the technique to be used. Exposure of the artery by incision is necessary; spinal anaesthesia for the lower limb has been recommended, and is to be preferred, but it can well be done under local anaesthesia. The vessel to be used for injection is commonly exposed by small transverse incision either at the elbow or just below the inguinal ligament. A blood-pressure tourniquet is usually necessary for the arm during the taking of the X-Ray (no special technique is required for this), for the medium is otherwise washed away too rapidly. A two-way tap ensures easier steady injection by the assistant, and the operator has a free hand for proximal compression of the vessel. For the upper limb 5-7 c.c. of diodone are needed; I2-I4 C.c. for the lower limb; if the opera- $\cong$ tion is done under local anaesthesia the patient will 3 complain temporarily of a burning pain in the $\stackrel{\mathbb{2}}{2}$ terminal field, and this indicates the extent of $c$. injection fluid needed. The field of usefulness of $\vec{F}$ arteriography is likely to be extended; at present $\stackrel{\text { के }}{\rightarrow}$ one can state that it gives much information in $\frac{}{6}$ Buerger's disease, and that it is valuable in locating $\frac{\bar{\sigma}}{\bar{\omega}}$. the sites of arterial block. It is of value in arterial $\frac{\text { क }}{\sigma}$ and arterio-venous aneurysmal studies. I have $\varrho$ found it possible in the arterio-venous aneurysm $\%$ to fill the artery by venous injection-a blood- $\vec{\circ}$ pressure cuff being inflated above the lesion. $\stackrel{\circ}{-}$ The fistula site, and the continuity of the vessel $\vec{\omega}$ is thus clearly indicated.

\section{Organic Vascular Disorders.}

\section{Arteriosclerotic gangrene.}

There have been no particular surgical advances $\stackrel{\omega}{\omega}$ in the treatment of this condition in recent years. $\vec{\rho}$ But it has become realised that the ageing have $\frac{}{I}$ not a creeping upward obliteration of the vascular $\vec{c}$ system-starting at the peripheral end-as is ฏ commonly imagined. A man of 60 may have as? normal a flow as the boy of $I 7$ (Kunkel and Stead). ${ }^{11}$ When gangrene ensues, even of a toe, it usually $\overrightarrow{0}$ means that there is an extensive lesion high uQ commonly a complete obliteration of the main arterial stream from the popliteal downwards Oft, the femoral artery itself is involved, and of opening is found filled with a fleshy red clot. Sappington and Fisher, ${ }^{23}$ in a pathological study of occlusive peripheral sclerosis have confirmed this. Indeed, the ability of the small vessels of the skin $\overrightarrow{\overrightarrow{0}}$ to dilate has been found to be usually normal; the 3 skin nutritional effects are due to the reduced rate of blood flow. Occasionally, the distal digital vessels appear to suffer particularly as in diabetes of long standing. "Arteriosclerosis is still the unknown" (Hart and Lisa). ${ }^{24}$ The surgeon's attitude is on the whole a more conservative one. A mere toe-tip gangrene does not demand imme- $\frac{\delta}{8}$ diate thigh amputation, for such patients, who otherwise become a burden to themselves and their 음 families, can often be improved. Usually they $D$ have severe associated coronary disease, and a crutch or artificial limb demands an excessive N effort on walking. The first essential for the threatened limb is rest; plenty of sleep is important, $\mathbb{O}$ and Ingram ${ }^{25}$ has shown that full vasodilation of ${ }^{N}$ the extremities occurs during sleep. Luminal is useful for this, and whisky and brandy are notoo harmful-indeed are being advocated deliberately in these cases. Smoking should, however, be $\stackrel{\oplus}{?}$ restricted, or preferably abandoned, for the peri- 0 pheral skin vessels are powerfully vasoconstricted. 


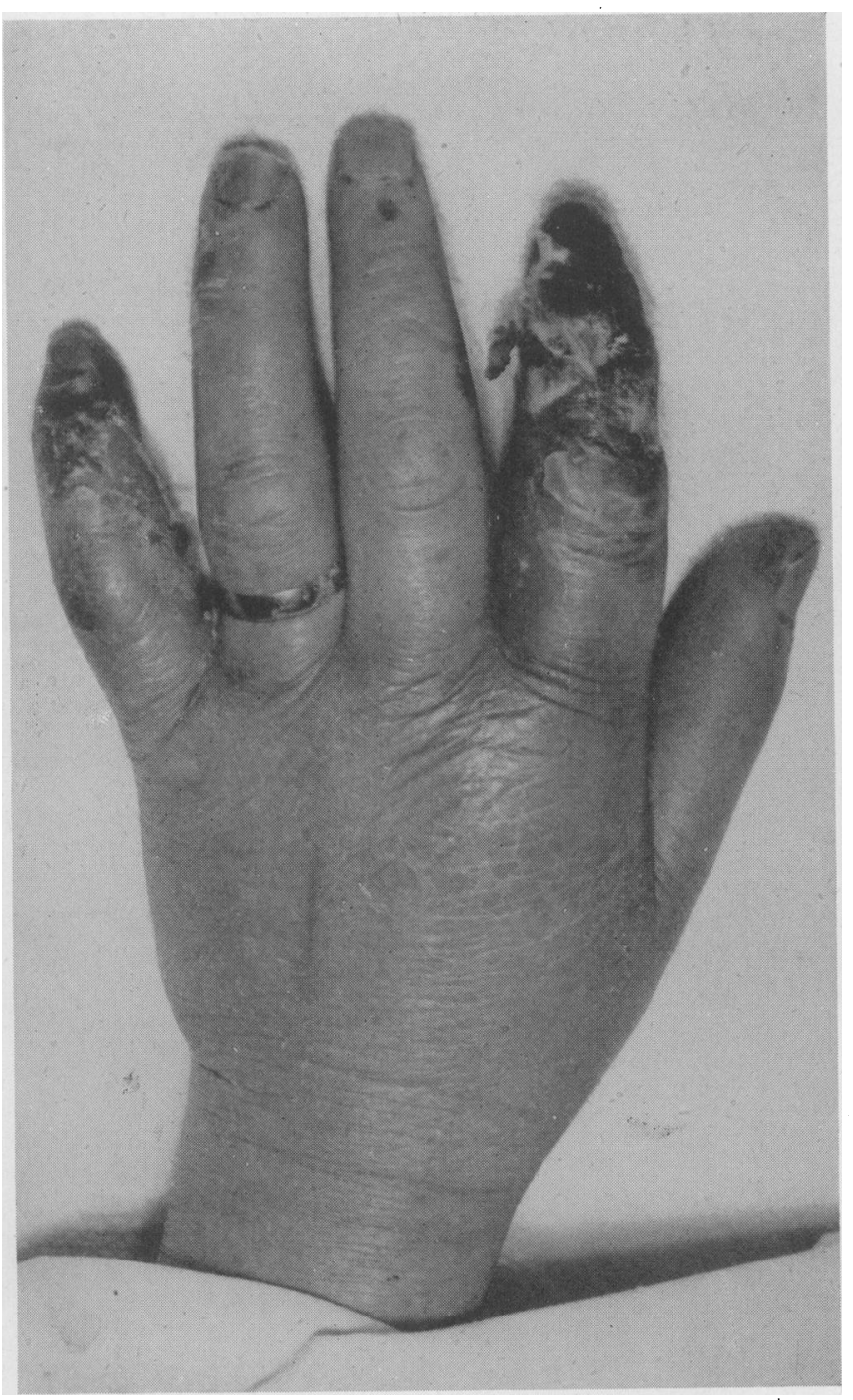

ARteriosclerotic Disease of digital vessels of hand in woman aged 73. Rare. Full radial and ulnar pulses present. Fore-arm amputation became necessary. Death later from coronary thrombosis.

Right-Femoral and Brachial ARteries (I 85x).-Stained to show muscle coats; note relative greater thickness of brachial artery. (The aorta consists of elastic tissue only; muscle coat thickens as the vessel descends. Nervous and hormonal control of the circulation thus chiefly affects the distal tree.)

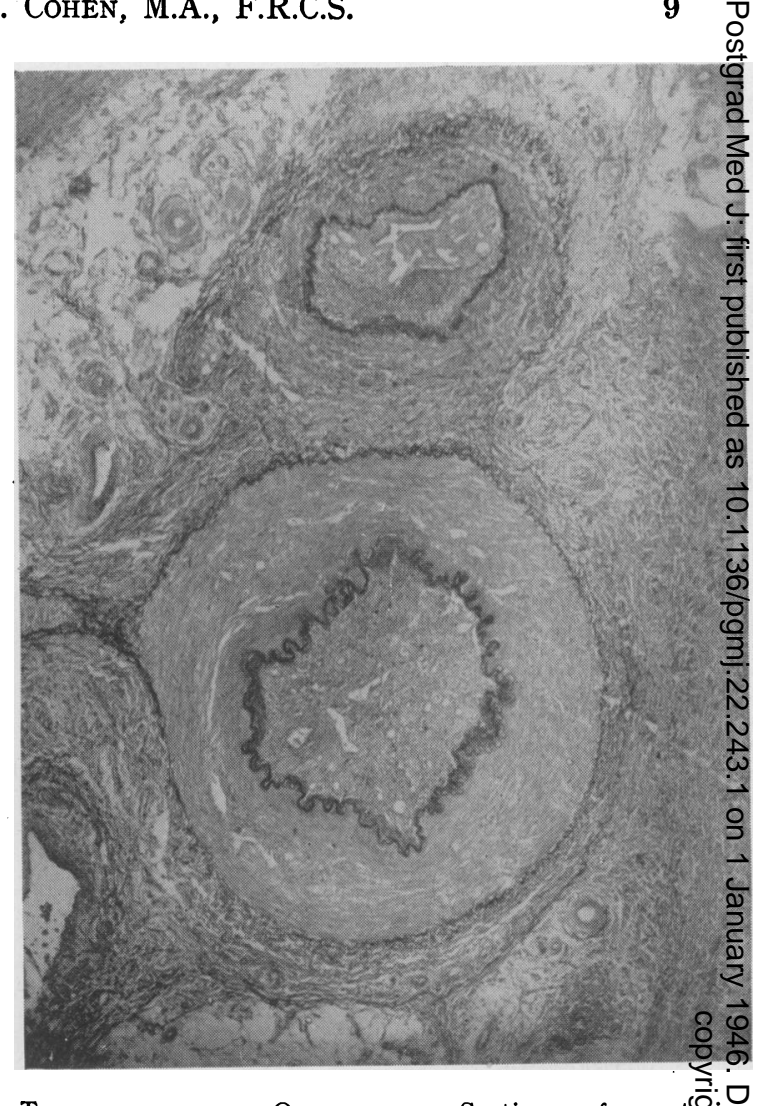

Thromboangirtis Obliterans.-Section of postêtiণ tibial artery and vein showing organisation and recañas isation. The dilated vaso-vasorum show as clear space्f in the media. Vein and artery are closely bound together by the abundant adjacent fibrous tissue. (Courtesy Professor Learmonth.)

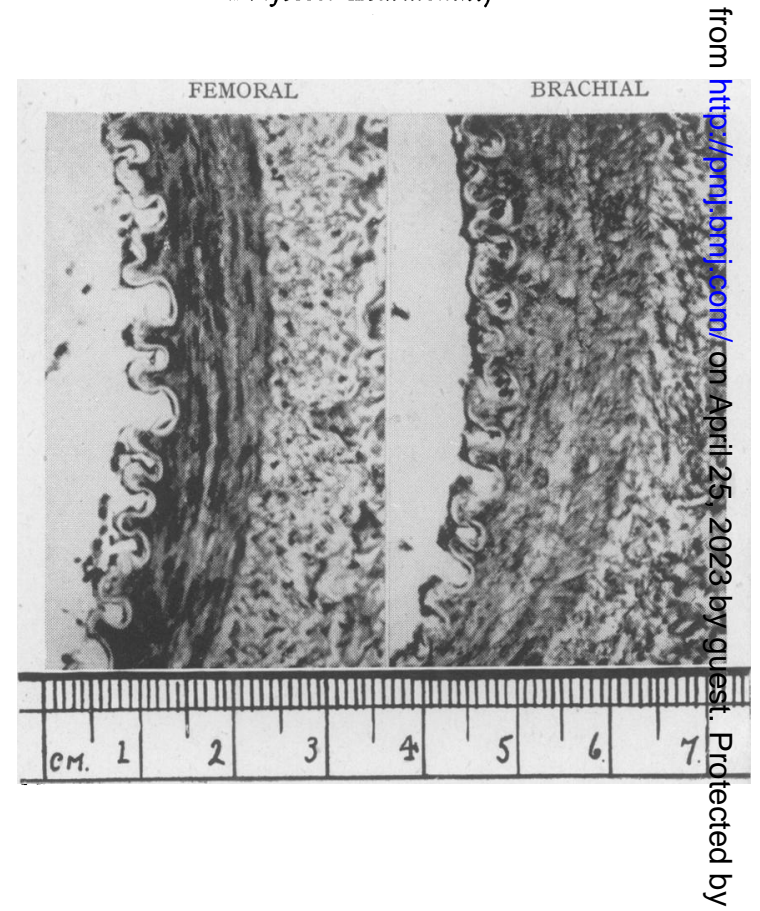


ARTERIOGRAM-Thromboangiitis Obliterans.

No popliteal block. The anterior tibial artery ends in distal third of leg (A); two interlacing collaterals continue along its vascular path. The posterior tibial (B) in its distal half has minute lumen and passes down in a wavy sepentine manner. Note remarkable development of tortuous collaterals. Connecting branches between anterior and posterior tibial vessels clearly shown.

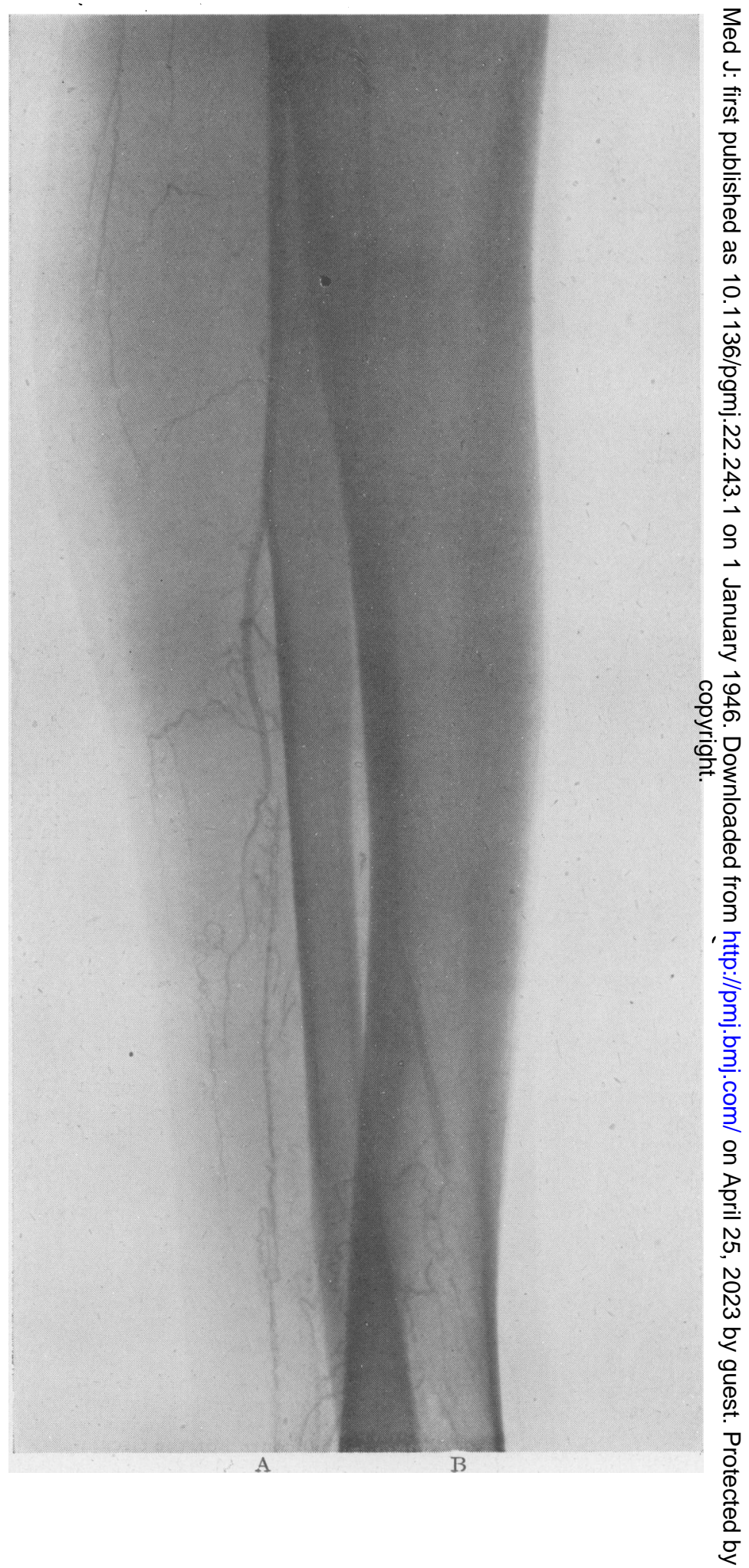


PERIPHERAL VASCULAR DISORDERS. Sol. M. CoHEN, M.A., F.R.C.S.

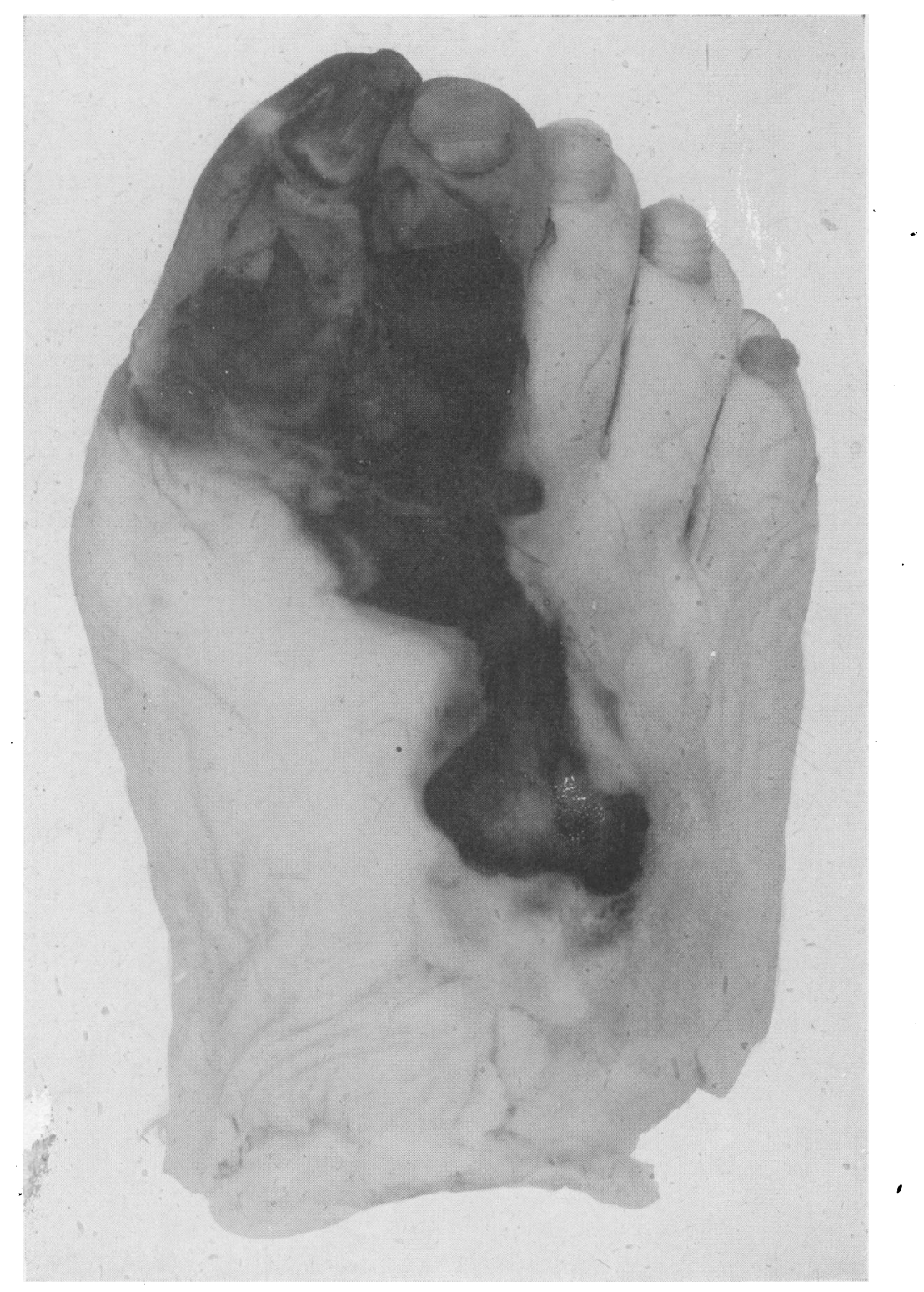

Arteriosclerotic Gangrene in a diabetic.

Note proximal wedge-like extension. The foot is involved proximal to the metatarsal heads-high amputation (thigh) is therefore necessary. (Guy's Hosp. Museum.) 

Good healing following bilateral sympathectomy and local amputations. Able to get about well on a bicycle, and has returned to his work as a musician.

-Gangrene followed "ingrowing toe nail" operation. Note scar plantar aspect big toe-due to operation for tendon infection. Six months later there was an extension of the disease. Despite sympathectomy "rest pain"; of the foot continued and below-knee amputation had to be performed.

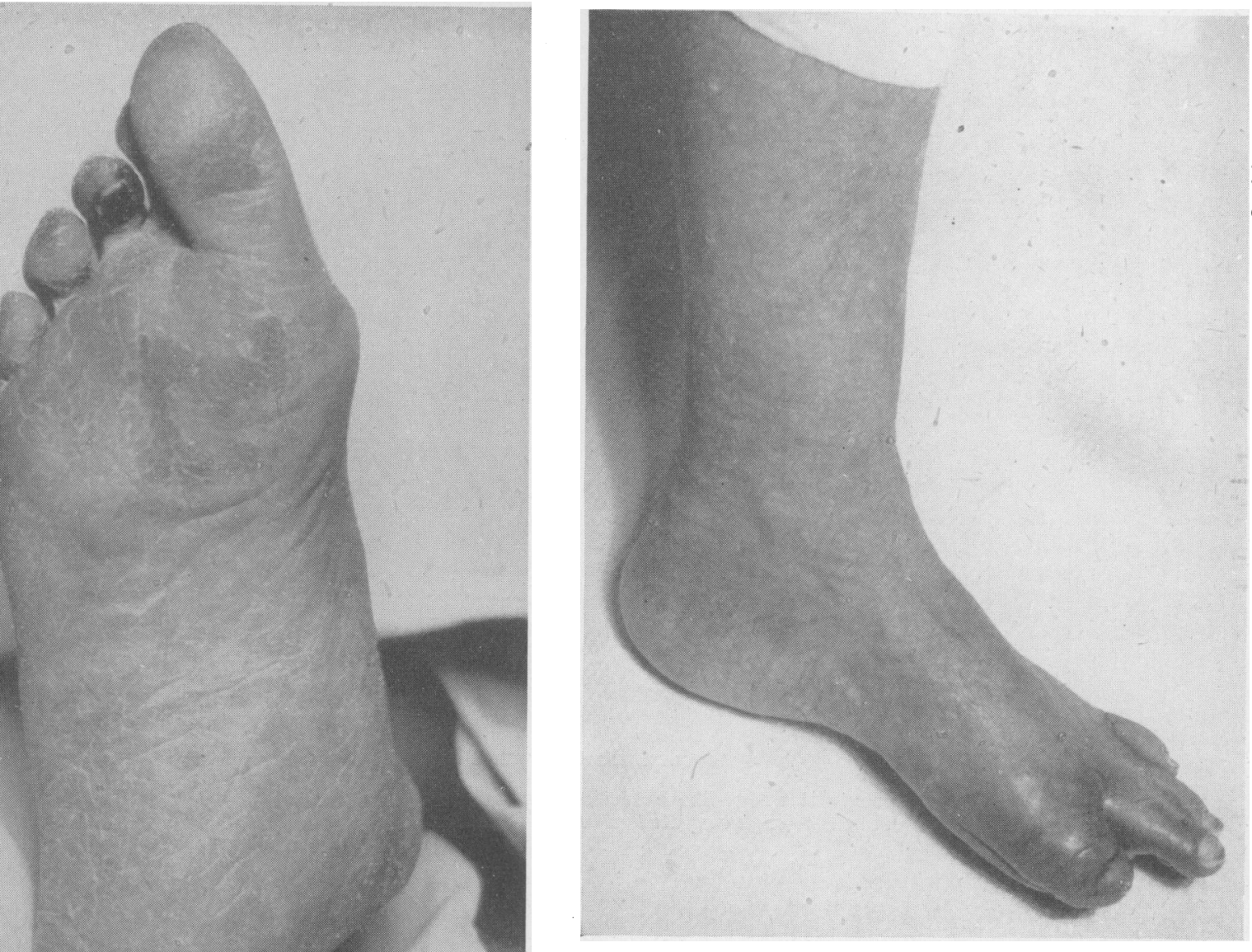

Left-Thromboangirtis Obliterans.-Gangrene of one toe. Dorsalis pedis pulse full. Other limb previously amputated. This toe gangrene cleared on conservative treatment. Note the disease may be present despite normal distal pulses. 
The haemoglobin should be watched; Pickering and Wayne ${ }^{26}$ have shown that anaemia in itself, without peripheral vascular disease, will cause intermittent limp symptoms. Breathing exercises should be taught. Recent evidence from war casualties suffering peripheral vascular lesions due to prolonged exposure to wet and cold, indicate its worth; the lymphatic and venous return from the limb are improved (Patterson and Anderson). ${ }^{27}$ "Reflex" vasodilatation Learmonth considers well worth while; the hot cradle to an arm or immersion of opposite limbs in water at $1 \mathrm{IO}^{\circ} \mathrm{F}$. twice daily for 20 minutes is certainly to be recommended. Or the hip "sitz" bath, as favoured by some for this purpose, may be used. Intravenous hypertonic saline injections-300 c.c. of 2 per cent solution, twice a week is a useful measure, for it has been shown that the blood flow in both skin and muscle are increased (Friendlander $e t a l$ ). ${ }^{13}$ My experience is that patients with intermittent claudication benefit considerably; the treatment has to continue several months. Buerger-Allen exercises should be conscientiously carried out. For the local lesion 20 per cent sulphanilamide suspension in glycerine or equal parts of spirit and glycerine, is a suitable dressing; the glycerine prevents drying and cracking, but penicillin cream is of value if there be local sepsis. The affected limb should be lightly bandaged in wool and kept exposed. It should not be iced, for as Lewis has shown, cold below $15^{\circ} \mathrm{C}$. definitely does harm. In many of the cases, the black toe, apparently completely gangrenous, sheds but a mantle of skin, much to one's surprise. Occasionally, when a line of demarcation is established, it is worth while completing nature's amputation; the tendon separates very slowly and its sheath tends to become infected.

Some of the patients.have considerable pain, and "peripheral sympathectomy" by crushing the mixed nerves has been recommended (White's operation). ${ }^{29}$ In the leg these nerves are exposed by incisions some 6 inches above the ankle jointthe subsequent anaesthesia and intrinsic muscle paresis of the foot does not disturb the patient. But such incisions often heal badly, and in my experience the operation is rarely worth while. Sympathectomy, as we have discussed, is a far better procedure for the severe rest pain; it does not help the intermittent claudication. For the frank gangrene - as Telford ${ }^{8}$ has stressed-it is of no value. But there seems no doubt that where there is threatened limb gangrene, sympathectomy gives, at times, a surprisingly gratifying result. Periarterial sympathectomy is now rarely practised; the results were disappointing. Femoral vein ligature in Hunter's canal (often called Oppel's operation) I have found a most valuable measure in some of these cases; the operation can be done under local anaesthesia. Glasser ${ }^{30}$ has recently reviewed II8 such ligations for occlusive arterial disease and finds it "of definite value in the prevention of gangrene and the alleviation of pain"; he ligates the superficial femoral vein just below the profunda branch.

When gangrene reaches the metatarsals, amputation becomes essential. It had been hoped by modern methods of limb management, and especially keeping the limb cool, that amputation through the leg might become possible. This has not been successful; and in the arteriosclerotic, amputation through the thigh still has to be the site of operation. The diabetic gangrene, as is well known, gathers infection easily; a spreading cellulitis ensues, and frequently there is gross tendon infection which is overlooked-(in laying open the sheath the tendon is better excised forthwith). It should be noted, from the peripheral vascular point of view, that all diabetics are not arteriosclerotic; they are not "sitting on powder barrels." The prognosis of the diabetic with extensive gangrene is poor; usually there is co-existent extensive coronary or cerebral atheromatosis. It has been shown that quite 50 per cent die within 2 years.

A good anaesthetist is required for the amputao tion in these very ill arteriosclerotics. Icee anaesthesia-as introduced some 4 years agohave frequently used; the method is painless? there is no shock and the flaps heal well provided they are not cooled excessively and sepsis is prevented. The method is, however, cumbersome. Gas gangrene, although it has not occurred in my series, has been described as following such icing. Such gas gangrene is, however, always a risk in the ageing-4.I per cent in 264 amputations (Bickel and Macey),, ${ }^{\mathbf{3 1}}$ for it has been shown that organisms can be cultured from the lymphatics around the vessels. Prophylactic anti-gas gangrene serum is thus a wise measure. "Physiological amputation" is at times useful when there is a rapid spreading gangrenous infection, and the patient's condition desperate. A tourniquet is applied, the limb iced, and many hours later when the general condition has improved, amputation is performed-if need be under icing anaesthesia.

\section{Thromboangiitis Obliterans.}

We know but little more of the aetiology of this distressing disease since the time when Leo Buerger first sorted out its pathology in 1908. The main findings of recent years are that the disease is not confined to Jews, but certainly is found with greater frequency in Polish Jews. Smoking is 
now regarded merely as an aggravating factor. $A$ conservative policy in treatment is strongly to be recommended; Samuels, ${ }^{19}$ in an experience of over 500 cases, has done major amputations on only four. Both arteries and veins are affected, and a "jumping" phlebitis-affecting small segments of veins-is found in 40 per cent of cases. Biopsy of such a vein segment is of great help in fixing the diagnosis; giant cell formations within the thrombus are diagnostic. Arteriography is particularly helpful and will mark out the sites of blockage, and filling defects. Boyd ${ }^{32}$ has divided the cases into proximal and distal types; and my experience fits in with his classification. In the proximal type the major vessels are involved-the popliteal artery is found filled with clot, and the vessel wall free from inflammatory degenerative change. "Thrombosis is a primary event and not consequent on intimal disease." Intermittent claudication is the usual presenting symptom. 'In the distal type, the disease starts in the small vessels of the foot, with characteristic intimal proliferation, thrombosis and organisation. "Orthopaedic conditions," such as "falling arches," the supposed "ingrowing toe-nail" are often the first complaints. With the years both forms of disease progress-and it is not sufficiently realised that the coronary or cerebral arteries are involved also. Some of these patients are intensely depressed and suicidal. The first essential is a period of rest in bed, with thorough overhaul-and Boyd points particularly at the tonsils, which I can confirm. Smoking must be absolutely prohibited-"your leg or your cigarette-which do you prefer?" Patients should be warmly dressed, and walking, just short of pain, encouraged. Toe amputations -at intervals - are frequently called for; in my experience the flaps heal well, despite little bleeding. Much of the misery and pain of waiting unnecessarily for nature's amputation is thus avoided. Occasionally a small sinus follows and indicates a local stump osteitis; removal of the bone end, using gigli wire so as to avoid bone splintering, will complete the healing. Persistent pain, rather than gangrene, sometimes demands amputation; a below-knee usually succeeds. The value of sympathectomy in this disease has been difficult to assess. Telford's results indicate that half of his 74 cases were enabled to return to work; de Takats, ${ }^{37 a}$ by resettling the patients in less active occupations, had good results in 37 out of 50 cases. Telford $^{8}$ also has found sympathectomy of definite worth in cases where the upper extremities subsequently become involved in the disease. Occasionally, one observes with disappointment that after sympathectomy one or more of the digitsapparently fairly "fit"- - develops gangrene; de Takats has pointed out that if paravertebral sympathetic block be done prior to operation, 爱 "drop of skin temperature" in such digits will be observed, and the march of events may be forecast? The dilatation of the more patent (healthier $\$$ digital vessels opens up easier channels for the. limited blood stream flow; the more disease areas are thus deprived of blood. Even sosympathectomy will still have been worth while.

\section{Embolism.}

This vascular catastrophe is uncommon; the diagnosis is easy if the condition be remembered:Opinion is against conservative treatment; thisw succeeds more frequently in the upper limb case $\frac{}{0}$ Embolectomy to be successful must be done withiff Io hours, otherwise mass muscle death will have followed. The dangers of "toxic" absorption from dead muscle has been well established in this war N Anuria in the embolus case has been observed and most surgeons on thinking back over theib cases can recall how very ill were their patients when attempting to save such an ischaemic limb $\vec{c}$ Pain is commonly regarded as heralding the catastrophe; but numbness, stocking anaesthesia and paresis of the limb is more often the first complaint. The onset of the pain does not necessarily coincide with the moment of embolions impaction, and even more important is the fact that the site of the pain and tenderness does noto necessarily locate the embolus. The popliteal fossa may be painful and tender, and yet the commono femoral artery at the site of division is the obstruction site (54 per cent of cases). The sphygmo $\mathrm{a}$ manometer cuff around the thigh is helpful; now oscillations are found if block is at the femoraP level. Arteriography has been used to locate the embolus. It is increasingly realised that secondary? clot formation, distal to the embolus, is what so ofters seals the fate of the limb; aspiration of the distal. vessel tree is thus particularly important. Vesse slings below the embolus site need to be carefully handled, for they will fracture the clot. For the saddle aortic embolus clot incisions of both femoral arteries, with suitable slings, and retrograde suction, 5 has been the method favoured. But more recently common iliac artery incision has given excellente. results; the vessel is approached by an extra N peritoneal paramedian incision (Murray). A point often overlooked in such embolus operations is that with blood stagnation venous clotting mayw follow and give rise to pulmonary emboli. Co\% incident vein ligature should always be considered@o When amputation is inevitable, it has to be borned in mind that these patients are often very ill? indeed, and icing anaesthesia, in my experience, 0 here has a place. Icing the limb may also be 
PERIPHERAI, VASCULAR DISORDERS. Sol. M. CoHEN, M.A., F.R.C.S.

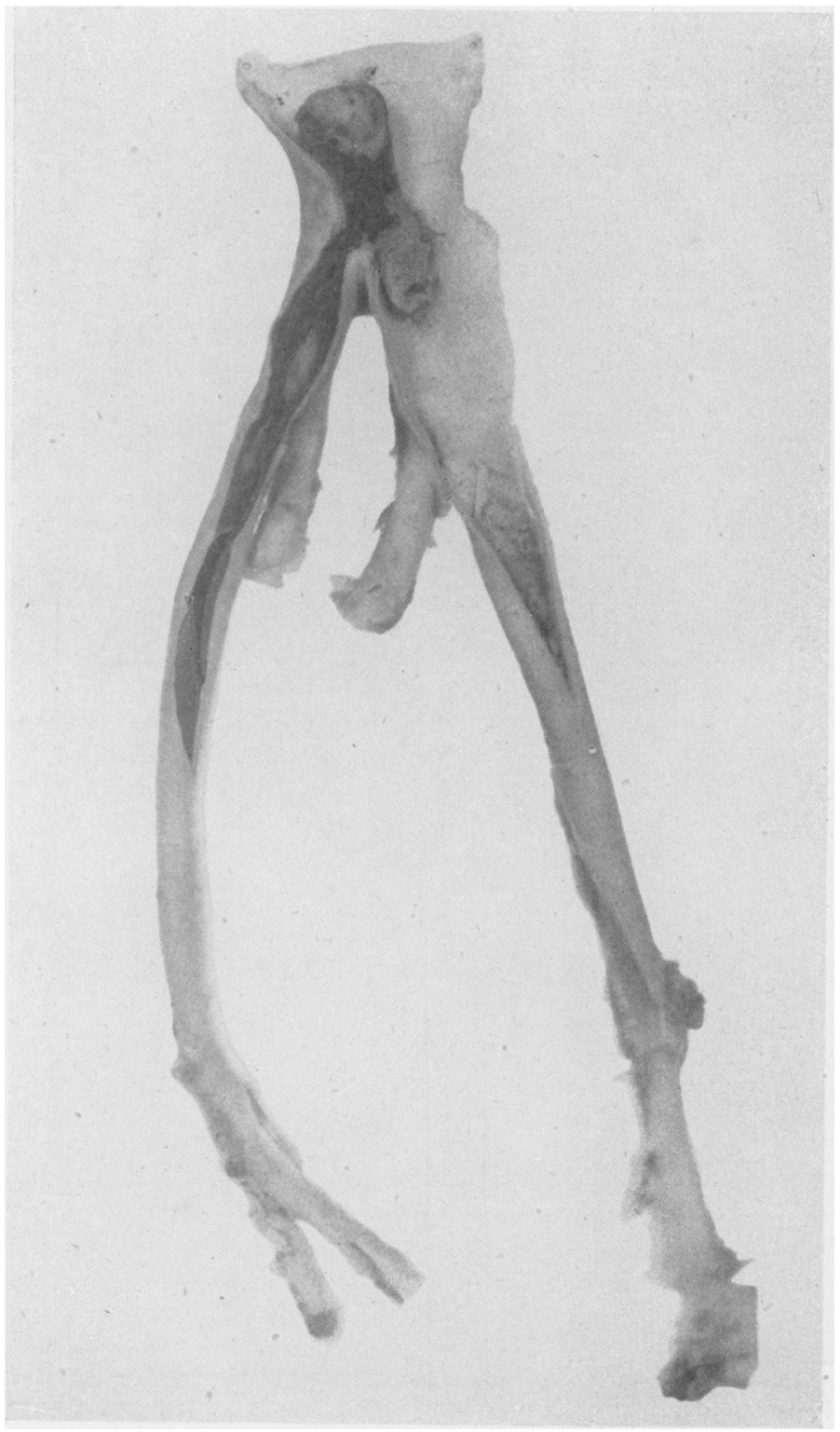

Sadde Embolus Clot at aortic bifurcation.

Note distal clot extension. For operation an extra peritoneal approach through the right common iliac artery is now favoured. (Guy's Hosp. Museum.) 


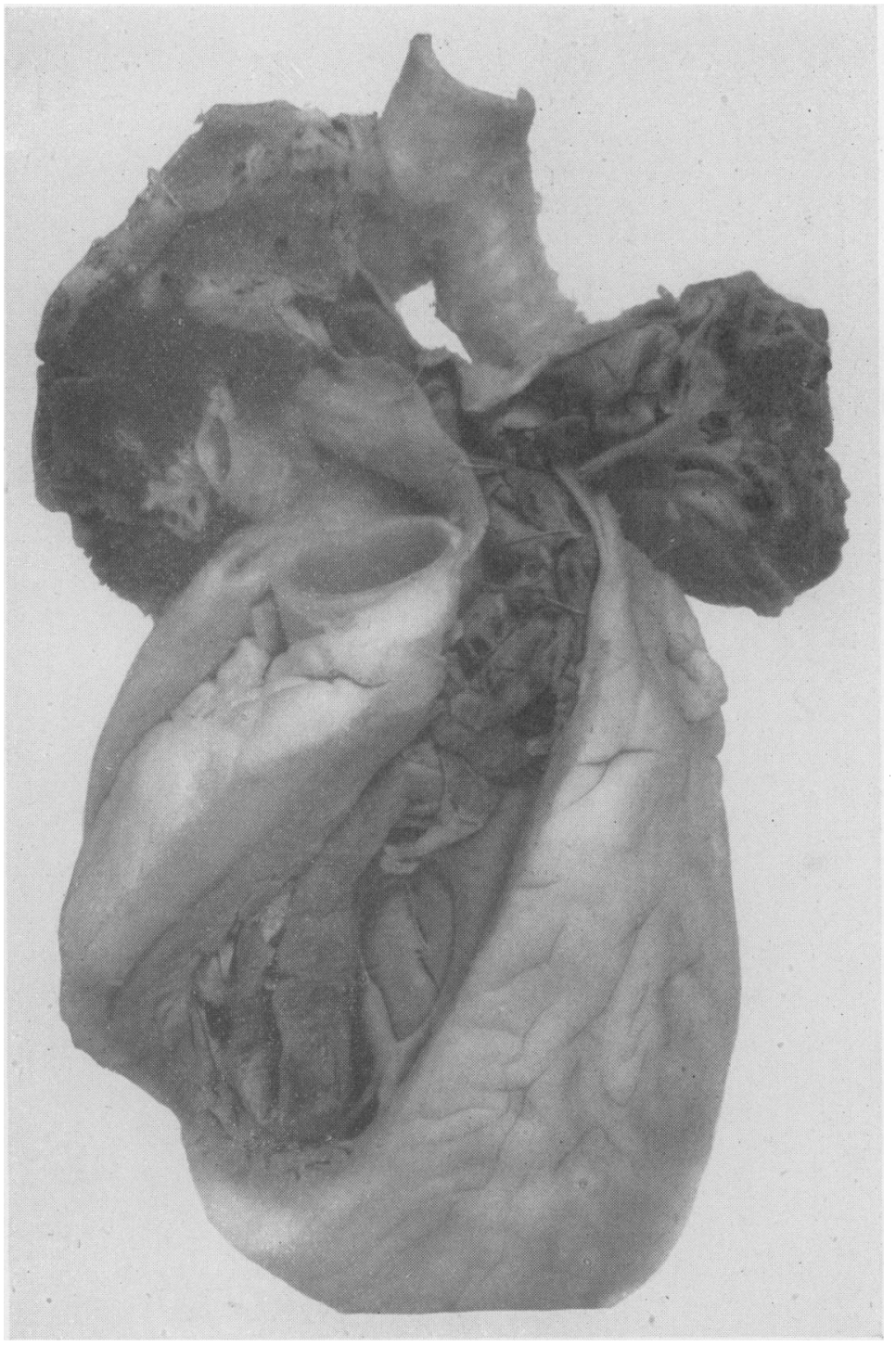

Puimonary Embolus.-The long entangled clot cramming the pulmonary arteries and the right ventricle is clearly slown. Iigation of the femoral or common iliac vein is likely to be more frequently practised in selected cases. (Guy's Hosp. Museun.) 
COARCTATION OF THE AORTA.

Rare congenital anomaly. Narrowing of isthmus between left subc clavian artery and the ductus arteriosus. Pressure raised in arms. (Guy's Hosp. Museum.)

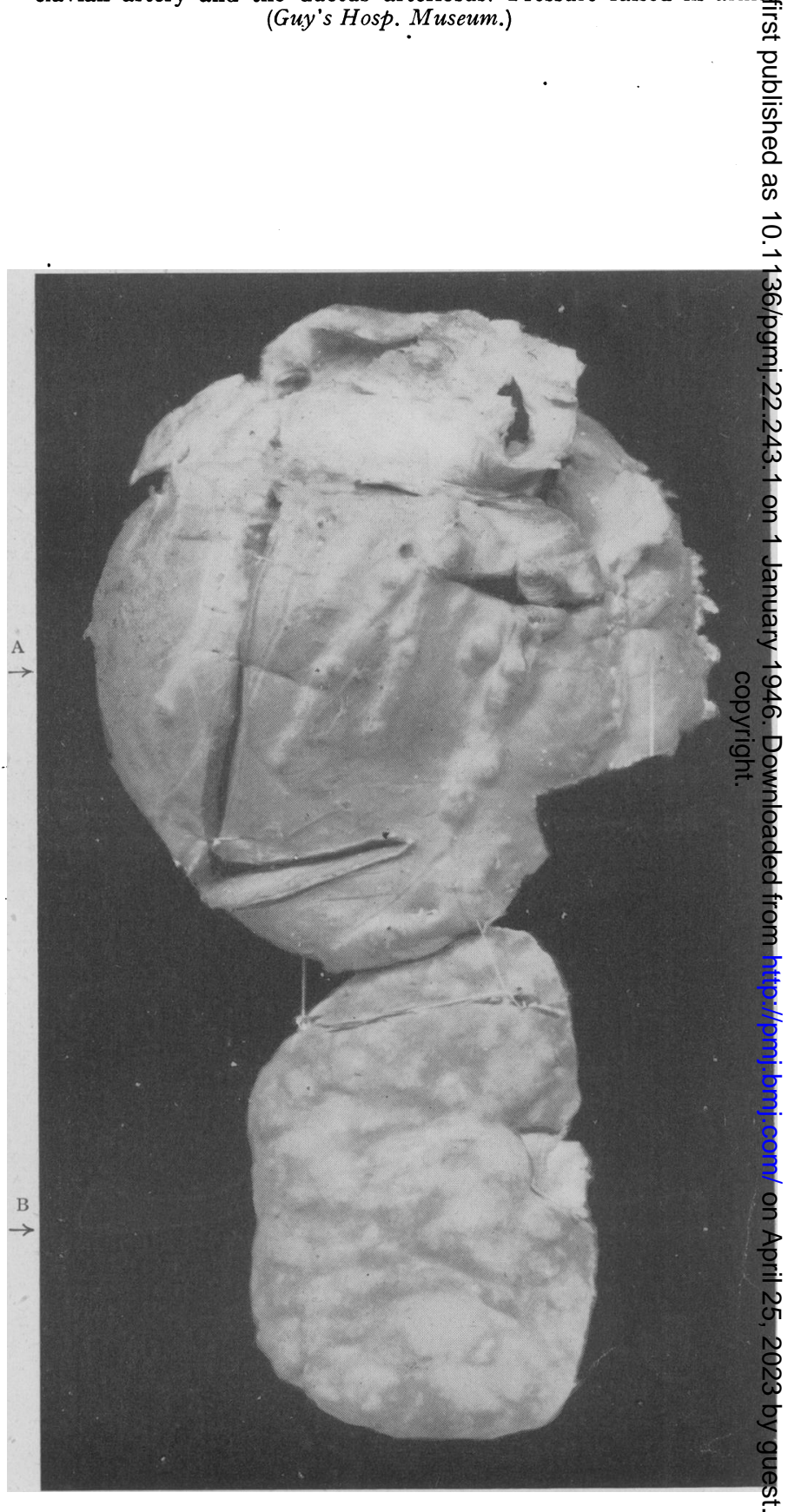

Coarctation of aorta. Pregnant woman, aged 27. Marked notching of ribs, due to the enlarged intercostal vessels.

(Reprinted by kind permission of Dr. J.W. Brown.)

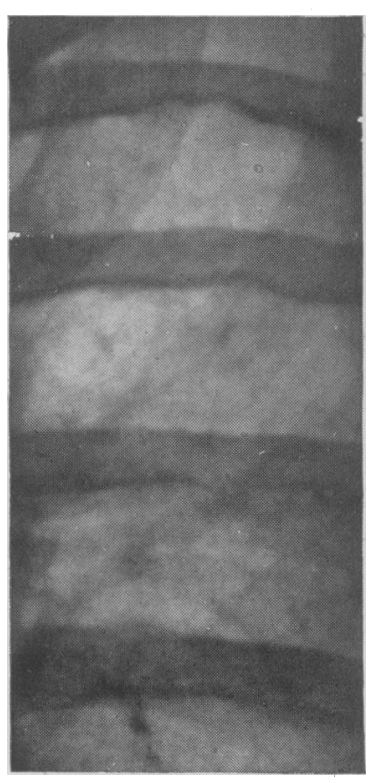

Periarteritis Nodosa.-An uncommon disease. Scattered nodules on heart (A) and kidney (B), clearly shown. Lesion consiste of patch of necrosis in media and subintixmal layers of the smallet arteries. Vessel rupture may lead to haemorrhage. Operated or occasionally, for symptoms suggesting an abdominal catastroph $\odot$ (Guy's Hosp. Museum.) 
Fig. 1
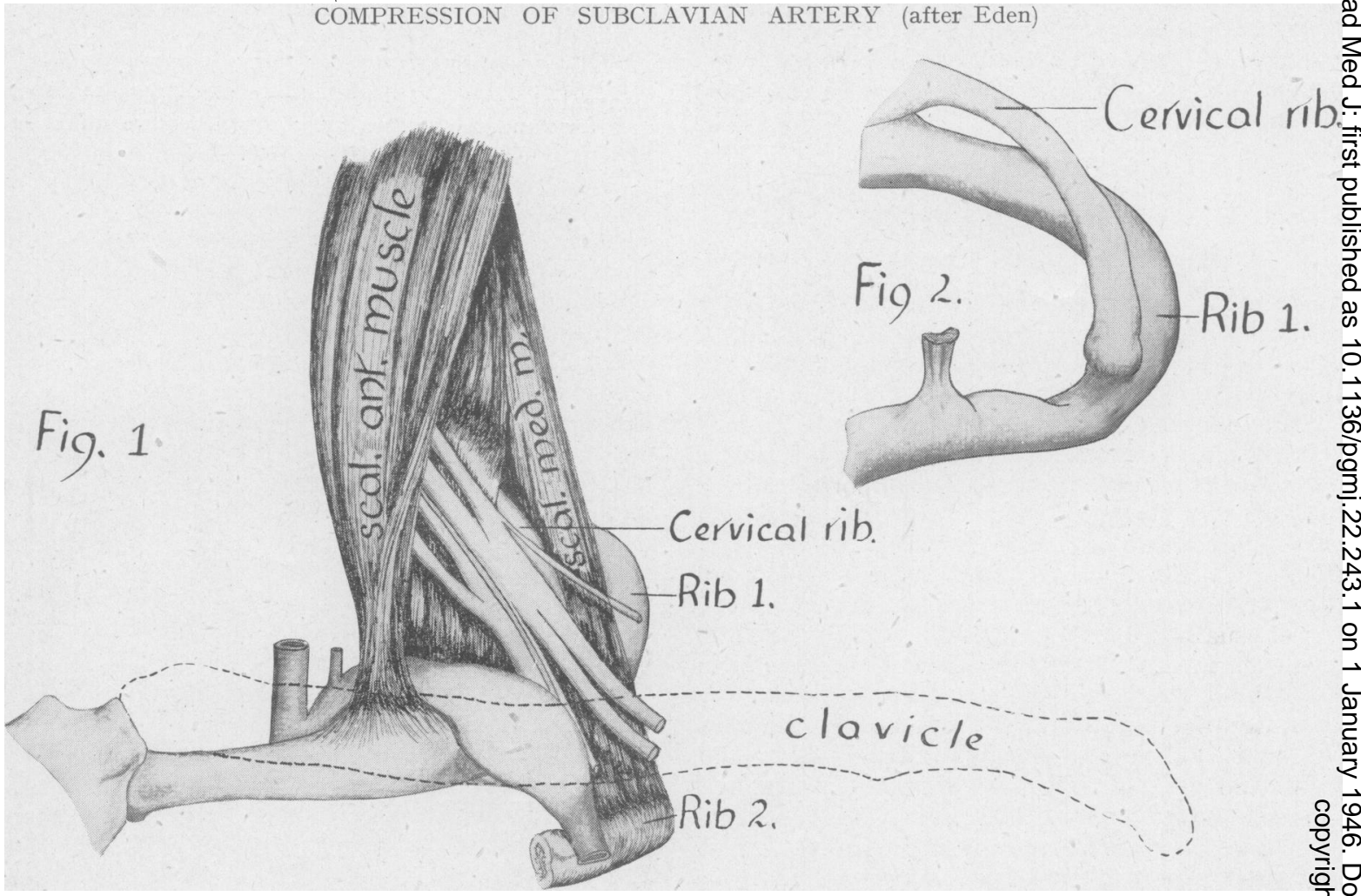

FIG. I.-Anatomical relations. Note aneurysmal dilation. Vessel may be intermittently compressed by clavicle FIG. 2.-Cervical rib. Note rib passed behind the brachial plexus. For vascular complications, as diagram indicates, a particularly long cervical rib will be necessary.
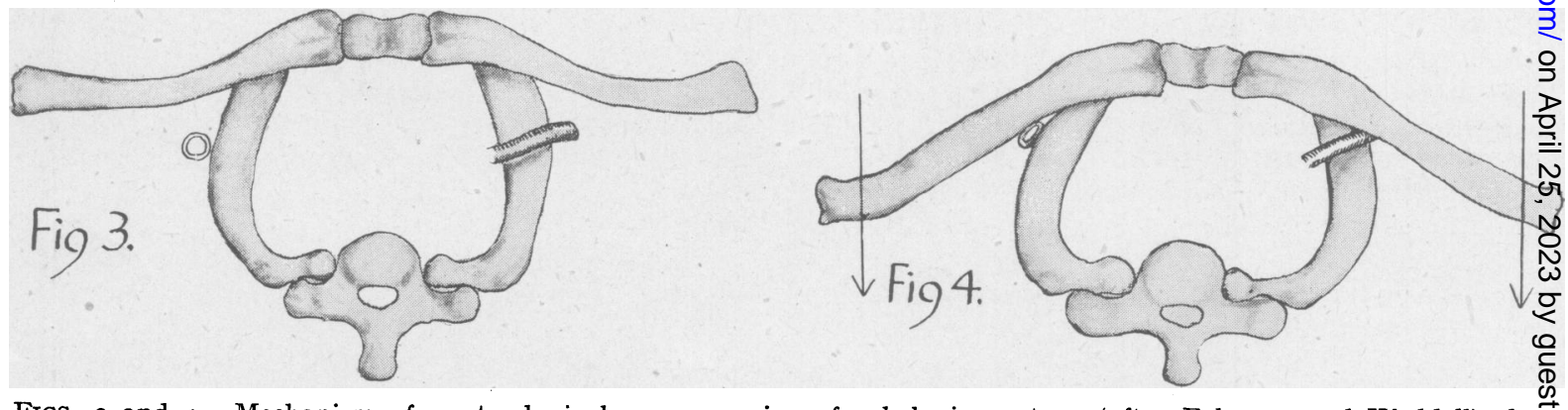

FIGS. 3 and 4.-Mechanism of costo-clavicular compression of subclavian artery (after Falconer and Weddell); by backward and downward movement of shoulders. Hyperextension of neck, too, may obliterate vessel; by scalenemuscles elevating anterior end of first rib. 
used to limit clotting whilst awaiting the preparation for the embolectomy operation. Occasionally, multiple arterial emboli in the same patient during convalescence, will tax the surgeon's skill and optimism (Macfarlane). ${ }^{39}$

\section{Costo-Clavicular Compression Thrombosis.}

Mechanical compression rather than "irritation of nerves" is now more commonly accepted as the causa causans of the "vascular complications" of the cervical rib. These cases are rare as compared to the nervous manifestations; it needs a long cervical rib to extend behind and affect the artery. Such disturbances-and this is the important recent finding - can, however, occur with a normal first rib. The theory of nerve irritation came to be invoked because it was found difficult to explain otherwise why obliteration of an artery, which could usually be ligatured with impunity, should result in severe ischaemic effects, even gangrene. Lewis and his co-workers clarified the issue by showing that intermittent trauma may damage the artery sufficient to provoke clotting; showers of small and even large emboli are then propagated into the distal arterial tree and account for the symptoms and nutritional effects. There are two points at which the subclavian artery may be thus intermittently compressed $(a)$ by the scalenus anticus muscle compressing it against a cervical rib (which, of course, lies behind artery and brachial plexus), (b) by clavicular compression against the first thoracic rib. Both factors may act in any one case. The surgeon must be armed with these facts, and to locate the compression site it may be advisable to start the operation under local anaesthesia. Scalenus anticus compression can be differentiated by paralysing the muscle by local injection; and it will be possible to observe and feel the clavicle compression effect by asking the conscious patient to brace the shoulders backwards and downwards. It is well known that the radial pulse may be thus obliterated in a large percentage of normal subjects; the vascular symptoms appear to follow only "when this compression is easily provoked." "Falconer and Weddell, ${ }^{40}$ Walshe, Jackson and Wyburn-Mason, ${ }^{41}$ have shown that an important step in the operation is thus the excision of. a segment of the first rib, behind the artery: to avoid opening the pleura the resection is usually a subperiosteal one. Where a cervical rib is present, Eden ${ }^{35}$ and Holling' $\mathrm{s}^{\mathbf{3 6}}$ advice is sound; the rib should be excised, for division of the scalenus anticus muscle alone cannot be relied on to prevent vascular trauma.
Functional Vasoconstrictor Disorders.

What has surgery to offer? The answer is difficult, for the process of winnowing disease from dysfunction is not yet complete. Raynaud's disease has been replaced by the term "RAYNAUD'S PHENOMENON," for it is recognised that within its orbit come a wide variety of vasospastic disorders. A local fault in the arteriolesan inborn or acquired hypersensitivity to cold-is commonly accepted as the underlying mechanism. In the simplest form the patient has "hereditary cold fingers" which blanche readily with cold; in the severer types there are intermittent attacks of pallor or cyanosis followed by rubor of the fingers, but no nutritional changes. When the attacks are frequent, nutritional disturbances such as pulp atrophy, nail distortion and finally tip-gangrene, supervene. The immediate results of "preganglionic" sympathectomy for the more severe group of cases have been excellent; but six months to a year later relapses have often followedalthough the attacks now are not as severe. According to Telford 40 per cent keep absolutely well. Sympathectomy brings other "unappreciated" advantages-the loss of sweating will help to keep the limb warm, cooling of the trunk or emotional disturbance will no longer reflexly constrict the digital vessel; - and the attacks are thus less frequent. Sympathectomy has, however proved of no value in the treatment of acrosclerosis or SCLERODACTYLY, which is oft regarded as a late end result of such intermittent spasm. Although the skin may become more supple, the blue claw-like stiff fingers with fixed contractures, are not improved. As is well known a more generalised scleroderma usually accompanies this disease; the skin of the face and trunk being "hidebound" by tightly stretched, immobile, often pigmented skin. The acquired type of cold sensitivity may sometimes be found in workers using rapidly vibrating hammers or chisels, and is known as "pneumatic hammer disease." Change of occupation is the cure. Such sensitivity may also follow a minor injury of hand or finger. These patients need firm reabling, and there may be a strong psychogenic basis; occasionally, however, despite $\frac{7}{0}$ contrary teaching, excision of a tender digital neuroma or even a malformed scar will give a good o result.

Surgical opinion may also be sought for the $\mathcal{N}^{\circ}$ condition of ACROCYANOSIS; patients have $\mathbb{\omega}$ blue cold hands or feet which sweat profusely and interfere with their work such as hairdressing, $\stackrel{0}{\varnothing}$ fishmongering, or the handling of food. Sympathectomy will relieve certainly the sweating; in $\stackrel{\mathscr{C}}{\rightarrow}$ the case of the feet the results are excellent, but 0 in the hands relapses--as in Raynaud's phenomena 
-may follow. Erythrocyanosis frigida is a form of "acrocyanosis" and is the term usually applied to such cases where the legs above the ankles-it is always bilateral-are involved. Often it is associated with an ugly cuff of thickened subcutaneous tissue just above the ankles. On the calf, itching indurated nodules oft develop and ulcerate; the condition is referred to as "Bazins disease." Telford and Simmonds ${ }^{38}$ have shown that fat necrosis, secondary to the ischaemia-is the cause of the lesion. Sympathectomy will improve the skin circulation, but the thickened skin cuff stays (Knight). ${ }^{34}$ In this category may well be included the cold blue limb of the poliomyelitis patientsympathectomy here gives good results and should be more often employed as a preliminary to stabilising operations on the foot. Occasionally the severe chilblain (Perniosis) will "earn" her operation-sympathectomy; Telford's results are good.

\section{Vasodilator Effects.}

ERYTHRALGIA. This is not a disease, but merely a term coined by Lewis ${ }^{28 a}$ to describe a painful, red, tender state of the skin following injury by a variety of agents. It is a local condition and may be provoked by chronic inflammatory states; conditions such as the prolonged healing as in infection with arterial disease; or the long lasting tissue insults due to repeated overcooling with unsuitable occupation, or as in chronic chilblains and erythrocyanosis. As such, the surgeon must know something of it. "Erythromelalgia" is now looked on, not as a malady, but as a severe manifestation of the erythralgic phenomenon. The pain nerve endings in erythralgia are in an hyper-excitable state; warmth, friction, walking, or dependency, will provoke pain. Common to all is the fact that a local vasodilationactive or passive (as in dependency) is thus induced; the nerve endings are hypersensitive to the increased hydrostatic pressure. Elevation and cold will thus relieve the pain of the patient-and explains why they usually sleep with their feet outside the bedclothes. The treatment in the first instance thus depends on dealing with the primary provoking cause. But there is a dilemma - the management of the local lesion will almost certainly demand an increased local blood flowbut that will cause pain. This only comes on when the temperature of the skin reaches a certain level-usually about $32^{\circ}$ to $34^{\circ} \mathrm{C}$.-measures to promote blood flow are thus stepped up just short of bringing on the pain. Controlled exercises are here of particular value. The intractable form, diagnosed as "erythromelalgia" is a very rare disease, "most physicians go through life without ever seeing a case" (Homans). ${ }^{\text {33a }}$ Telford has done sympathectomies on five such cases, with immediate and permanent cure. Erythromelalgia, in the past, has often been the mistaken diagnosis in cases where the reddening has in fact been due to the "rubor" of serious organic arterial disease. The cardinal distinguishing findings in such an erythromelalgic limb may thus be repeated-the warm limb (in the painful stage), the full pulses, the increased pain on dependency and warmth, the absence of paling on elevation or exercise.

\section{Post-Traumatic Painful States.}

The persistently painful extremity without apparent cause after injury, is still a great problem. At present there is no certainty even as to the vascular changes. Homans (33a) maintains that there is such a condition as "chronic reflex arterial spasm," and this affects the nutrition to the skin, to the nerves, to the bone; hence the multitude of terms applied to this group of disorders. "Causalgia," "Reflex dystrophy of the extremities,", Traumatic osteoporosis, "Sudeck's atrophy." Lewis $^{28 c}$ and de Takats, ${ }^{37 b}$ however, have found an increased flow in the affected extremities-and this is certainly true in causalgia (as Homans ${ }^{33 b}$ recently agrees). This difference of opinion as to the vascular findings, is itself an indication that "altered" blood flow will not explain the mechanism of the pain. The problem is well discussed in a recent paper by Doupe, Cullen and Chance. ${ }^{7}$ They divide the cases into three groups (I) Psychogenic, (2) Causalgic, (3) Dystrophy (disturbance of nutrition). We need not discuss these in detail, but may note that in the psychogenic, owing to disuse of the limb, nutritional disturbances may well supervene and the patient have genuine pain (dystrophic pain). The causalgic group of patients - -which usually follow associated median or sciatic nerve injuries-are important, as sympathectomy gives certain relief according to these authors. Sympathetic block may be used as a preliminary therapeutic test. Causalgic pain is distinctive; it is burning hot, very severe, and easily provoked by warmth-rather like the erythralgic state. Reflex vasodilation does not produce relief; and this indicates that sympathectomy does not relieve purely by its vasodilating effect. Moreover, as there are no sensory fibres in the sympathetic, there was need of an explanation as to how such sympathectomy worked. These authors bring evidence to show that the causalgic pain is due to cross stimulation of the sensory fibres by the efferent impulses in the svmpathetic fibres. The dystrophic pain is of dull aching character, usually more marked at night, and made worse by movement. They suggest that the pain is due to dis- 
turbances of local nutrition; and by that imply that we are apt to overlook the other factors affecting the nutrition of a part, such as venous drainage, lvmphatic drainage, and of course the fact that the blood supply of a part will depend on its use. We have to bear in mind that nutritional defects, even osteoporosis of bone, can be found in patients who have no pain whatsoever. The deduction is reasonable-the exaggerated pain occurs when the injury has been implanted on a psychogenic soil.

We gather a lesson. The mind is the man; and it is old but true that "the bodies of men are dependent on their spirits." The surgeon in his treatment of peripheral vascular disorders must not overlook this. There must ever loom before us the simple truth that we treat ill individuals rather than their ills.

\section{REFERENCES}

I. $\mathrm{COHN}, \mathrm{E}$ J. et. al. (1944) J. Clin. Invest, 23, $4 \mathrm{I7}$

1. LOEWE, L. ROSENBLATT P. and LEDERER, M. (1942), Proc.

Soc. Exper. Biol. and Med., 50, 53 .
3. BLAKEMORE, A. H., and LORD, J. W. (19.45), J. Amer. Med. Ass., 127, 685

4a.GOETZ, R. H. (1943), S. Afr. J. Med. Sc., 8, 65.

4 b.GOET7, R. H. (1945), S. Afr. Med. J., 24, 91.

5. BURTON, A. C. (1939), Am. J. Phvsiol., 127, 437 .

7. DOUPE, J., CULLEN, C. H., and CHANCE, G. Q. (I944), J. Neurol. Psvchiat., 7, 33 .

Psychiat., 7, 33.
8. TELFORD, E. D. (1944), Proc. Roy. Soc. Med., 37, 621 .

9. WILKINS, R. W., DOUPE, J., and NEWMAN, H. W. (1938), Clin. Sc. $3,+03$

ro. SILBERT, S. (1938), J. Mount. Sinai Hosp., 5, I28.
11. KUNKEL, P., and STEAD, E. A. (1938), J. Clin. Invest., 17, 715. 12. ABRAMSON," D. I. (1944), "Vascular Responses in the Extremities of Man in Heaith and Disease," Chicago.

I3. FRIEDLANDER, M., SILBERT, S., and BIERMAN, W. (1940), Amer. J. Med. Sc., 199, 657 .

14. GRANT, R. T., and PEARSON, R. S. B. (1938), Clin. Sc., 3, I I9.

15. BARCROFT, H., BONNAR, M. McK. EDHOLM, O., G., and EFFRON, A. S. (1943), J. Physiol, 102, 21 .

I6. GASK, G. E., and ROSS, P. J. (I937), "The Surgery of the Sympathetic Nervous System," London.

17. SMITHWICK, R. H. (1940), Arch. Surg., 40, 286.

18. LAKE, N. C. (1944), Brit.Med. J., 1, 843. of the Peripheral Arteries," New York.

20. KRAMER, D. W. (1940), "Manual of Peripheral Vascular Disorders," Philadelphia.

21. COLLENS, S., and WILENSKY, N. D. (1936), Am. J. Surg., 34, 7r. 22a.LEARMONTH, J. R. (1944), Lancet, 2, $75^{\circ}$.

22b.LEARMONTH, J. R. (I943), Edin. Med. J., 50, I40.

23. SAPPINGTON, S. W., and FISHER, W. R. (I942), Arch. Path., 34, ڤै 24. HART, J. F., and LISA, J. R. (1944), New York State J. Med., 44, 25. INGRAM, P. W. (1936), Edin. Med. J., 43, 672 .

26. PICKERING, G. W., and WAYNE, E. J. (I933), Clin. Sc., 1, 305.

27. PAT TERSON, R. H., and ANDERSON, F. M.' (1945), Surg. Gynec. Obstet. 80, $\mathrm{I}$.

28a.LEWIS, T. (1934), "Clinic-1 Science," London.

28b. LEWIS" T. (936)" "Vascular Disorders of the Limbs," London. 28c. LEWIS, T. (I942), "Pain," London.

29. WHITE, J. C. (1940), "The Autonomic Nervous System," New York. N 30. GLASSER, S. T. (I945), Arch. Surg., 50, 56.

3r. MACEY, H. B., and BICKEL, W. H. (1942), Sur. Gynec. Obstet., 74, $82 \mathrm{I}$.

32. BOYD, A. M. (1938), St. Bart's Hosp. Rep., 71, $15 \mathrm{I}$.

33a.HOMANS, J. (1939), "Circulatory Diseases of the Extremities," New York.

33b.HOMANS, J. (1943), Am. J. Med. Sc., 205, 313.

34. KNIGHT, B. C. (1938), St. Barts. hosp. Rep. (1938), 71, 173

35. EDEN, K. C. (1939), Brit. J. Surg., 27, iाr.

36. HOLLING, H. E. (1939), Guv's Hosp. Rep., 89, 285.

37a. de TAKATS, G. (1944), Surg. Gynec. Obstet., 79, 359.

37b. de TAKATS G. (I943), Arch. Neurnl. Psychiat., $50,318$.

38. TELFORD, E. D., and SIMMONDS, H. T. (1938), Brit. J. Surg., 25,

39. MacFARLANE, J. A. (1940), Brit. Med. J., 1, 97 r.

40. FALCONER, M. A., and WEDDELL, G. (1943), Lancet, 2, 539. 4r. WALSHE, J. M. R., JACKSON, H., and WYBURN-MASON, RO (1944), Brain, 67, 14r.

\section{THE SURGICAL MANAGEMENT OF PERIPHERAL VASCULAR DISORDERS PART II}

VASCULAR TRAUMA

is being published in the February issue of the Journal. 